\title{
P165: Perception of health care employee related to handwashing practice and insertion of the patient in this context
}

\author{
MM Baraldi ${ }^{*}$, C Santoro $^{1}$, C Scmitt ${ }^{1}$, M Simoneti ${ }^{1},{\text { C } \text { Lovatto }^{2}}^{2}$ \\ From 2nd International Conference on Prevention and Infection Control (ICPIC 2013) \\ Geneva, Switzerland. 25-28 June 2013
}

\section{Introduction}

Considering that handwashing responsabilityis mainly on health area professionals, the survey of employees' perception helps to orientate the implementation of educational measures in the promotion of improvements and and can also offer subsidies to stimulate patients' active participation in the search for health.

\section{Objectives}

Evaluate the health care employees perception regarding the best practices of handwashing, including the patient involvement in the shared responsability of this handwashing practice

\section{Methods}

It is about a descriptive, quantitative study performed at a midsize, private hospital located in São Paulo, Brazil.

Among the actions performed in the Annual Handwashing Campaign in 2012, pamphlets with closed questions were distributed, allowing the evaluation of 363 healthcare employees.

The variables for evaluation were considered: the importance of the 5 moments practice, the performance of handwashing opportunities, the importance given to the patient involvement, handwashing as part of care and the quality of alcohol gel.

\section{Results}

The analysis of collected data has showed that $99 \%$ of employees consider of "much importance" the 5 Moments practice, $58 \%$ consider fulfill $100 \%$ of opportunities. When evaluated the importance given to the patient involvement in the improvement process, $93 \%$ of the employees consider it very important, $3 \%$ indifferent and $4 \%$ refer moderate importance. $100 \%$ of the employees consider that handwashing is part of the health process. $81 \%$ of these consider that the family and patient proactivity help increase the implementation of handwashing measures, while $19 \%$ of the employees do not agree. The employees evaluated the quality of alcohol gel as: $61 \%$ very good and $38 \%$ good.

\section{Conclusion}

The results found show a homogeneous awareness on the practice of handwashing and also that the perception of the importance of the patient participation in the shared responsability already is a fact, which allows the implementation of new multiprofessional strategies, stimulating the patient to take an active part in his own care.

\section{Disclosure of interest \\ None declared.}

\section{Author details \\ ${ }^{1}$ Scih, Alemão Oswaldo Cruz Hospital, São Paulo, Brazil. ${ }^{2}$ Uti, Alemão Oswaldo Cruz Hospital, São Paulo, Brazil.}

Published: 20 June 2013

doi:10.1186/2047-2994-2-S1-P165

Cite this article as: Baraldi et al:: P165: Perception of health care

employee related to handwashing practice and insertion of the patient

in this context. Antimicrobial Resistance and Infection Control 2013

2(Suppl 1):P165.

${ }^{1}$ Scih, Alemão Oswaldo Cruz Hospital, São Paulo, Brazil

Full list of author information is available at the end of the article

(c) 2013 Baraldi et al; licensee BioMed Central Ltd. This is an Open Access article distributed under the terms of the Creative Commons Attribution License (http://creativecommons.org/licenses/by/2.0), which permits unrestricted use, distribution, and reproduction in any medium, provided the original work is properly cited. 